\title{
NUEVOS DATOS EN TORNO A LA VIRGEN DE LA LECHE DE ALONSO CANO EN GUADALAJARA
}

El bellísimo lienzo de Alonso Cano guardado en el Museo Provincial de Guadalajara (Fig. 1) puede considerarse como una obra cumbre dentro de la producción del maestro granadino. Obra por tanto de singular importancia, sin embargo aún hoy se desconoce una parte de la historia del lienzo, desde su ubicación original hasta la que ocupa hoy en día en el museo alcarreño.

Tanto Wethey ${ }^{1}$ como Pérez Sánchez ${ }^{2}$ aluden a los antiguos catálogos del Museo de Guadalajara. Las vicisitudes de esta institución ${ }^{3}$ comenzaron prácticamente desde su nacimiento. Tras la desamortización, y a instancias de la Sección Segunda de la Comisión Estatal de Monumentos, los lienzos recuperados de la desamortización se establecen el antiguo Convento de la Piedad de Guadalajara ${ }^{4}$, por entonces Diputación Provincial. De $1845^{5}$ data un catálogo previo por el que conocemos que el lienzo estaba situado en la Sala Cuarta, atribuido correctamente a su autor y con la mejor consideración.

$\mathrm{Al}$ año siguiente, en 1846, el lienzo es catalogado ${ }^{6}$ con el número de inventario 280, número actualmente visible, y en que se constata también el mal estado de conservación que debía presentar, caso afortunadamente resuelto en nuestros días.

Hemos de esperar a 1902 para ver una reapertura del Museo, fecha en que se edita el citado catálogo de Baquerizo. La pérdida de obras de arte se hace patente, y prueba de ello es la reestructuración que sufre el catálogo de 1846; así, el lienzo de Cano pasa a tener el número 213 de inventario. Para conocer su emplazamiento actual hay que esperar a $1973^{7}$.

Sin embargo, hasta ahora se desconocía ${ }^{8}$ el lugar de origen del lienzo. Pérez Sánchez ${ }^{9}$ apunta que el lienzo debió de proceder de alguno de los conventos de la zona de Guadalajara, y a la aportación que aquí hacemos es situarla en el Convento del Carmen de Guadalajara, conocido como Convento de la Epifanía ${ }^{10}$.

En los inventarios de Desamortización del Archivo Histórico Provincial de Guadalajara se conservan los índices del Convento del Carmen ${ }^{11}$. Con el número 9 encontramos la siguiente referencia:

9. María Santísima dando el pecho a su hijo. Más de vara y media por más de una vara.

\footnotetext{
1 Wethey, Harold E., Alonso Cano, Painter, Sculptor, Architect, Princeton, 1955, p. 162.

${ }^{2}$ Pérez Sánchez, Alfonso E., The Golden Age of Spanish Painting, Royal Academy of Arts, London, 1976, p. 69, n. ${ }^{\circ}$ cat. 51.

${ }^{3}$ Para ver los problemas del Museo remitimos a Carmelo Baquerizo, Catálogo de los Cuadros de Pintura, Esculturas y Monedas existentes en el Museo establecido en el Palacio de la Excelentísima Diputación provincial, Guadalajara, 1902.

${ }^{4}$ El edificio original corresponde al Palacio de Don Antonio de Mendoza, obra del segoviano Lorenzo Vázquez. Para más información ver: Rodríguez Rebollo, Ángel, El palacio de Don Antonio de Mendoza en Guadalajara, Archivo Español de Arte, en prensa.

5 Archivo Provincial de Guadalajara, Comisión de Monumentos, Caja 2. Nomenclatura de los cuadros que existen en el Museo Provincial de esta capital, clasificados en la forma mencionada por la Sección $2^{a}$ de la Comisión Central.

${ }^{6}$ Archivo Provincial de Guadalajara, Comisión de Monumentos, Caja 2, catálogo manuscrito: Comisión de Monumentos Históricos y Artísticos de la Provincia de Guadalajara. Sección Segunda. Catálogo de los Cuadros que existen (...).

7 Varios autores, Museo Provincial de Guadalajara. Guía de la Sección de Bellas Artes, Guadalajara, 1986, p. 17.

8 Se publicó en el año 1998 un artículo sobre la procedencia de algunos lienzos del Museo de Guadalajara. Sin embargo, creo que la localización del cuadro de Cano no es correcta. Para más información ver: Batalla Carchenilla, Cesar M. ${ }^{\mathrm{a}}$, «Procedencia de las obras del Museo Provincial de Guadalajara», Actas del VI Encuentro de Historiadores del Valle del Henares, Alcalá de Henares, Noviembre de 1998, págs. 599-611.

9 Pérez Sánchez, op. cit., p. 69.

${ }^{10}$ Layna Serrano, Francisco. Los Conventos antiguos de Guadalajara, Guadalajara, 1937.

1 AHPGU, Sección Desamortización, Caja 5, n. ${ }^{\circ} 12$, año 1811 , Inventario de los quadros existentes en el convento del Carmen de la Ciudad de Guadalajara.
} 


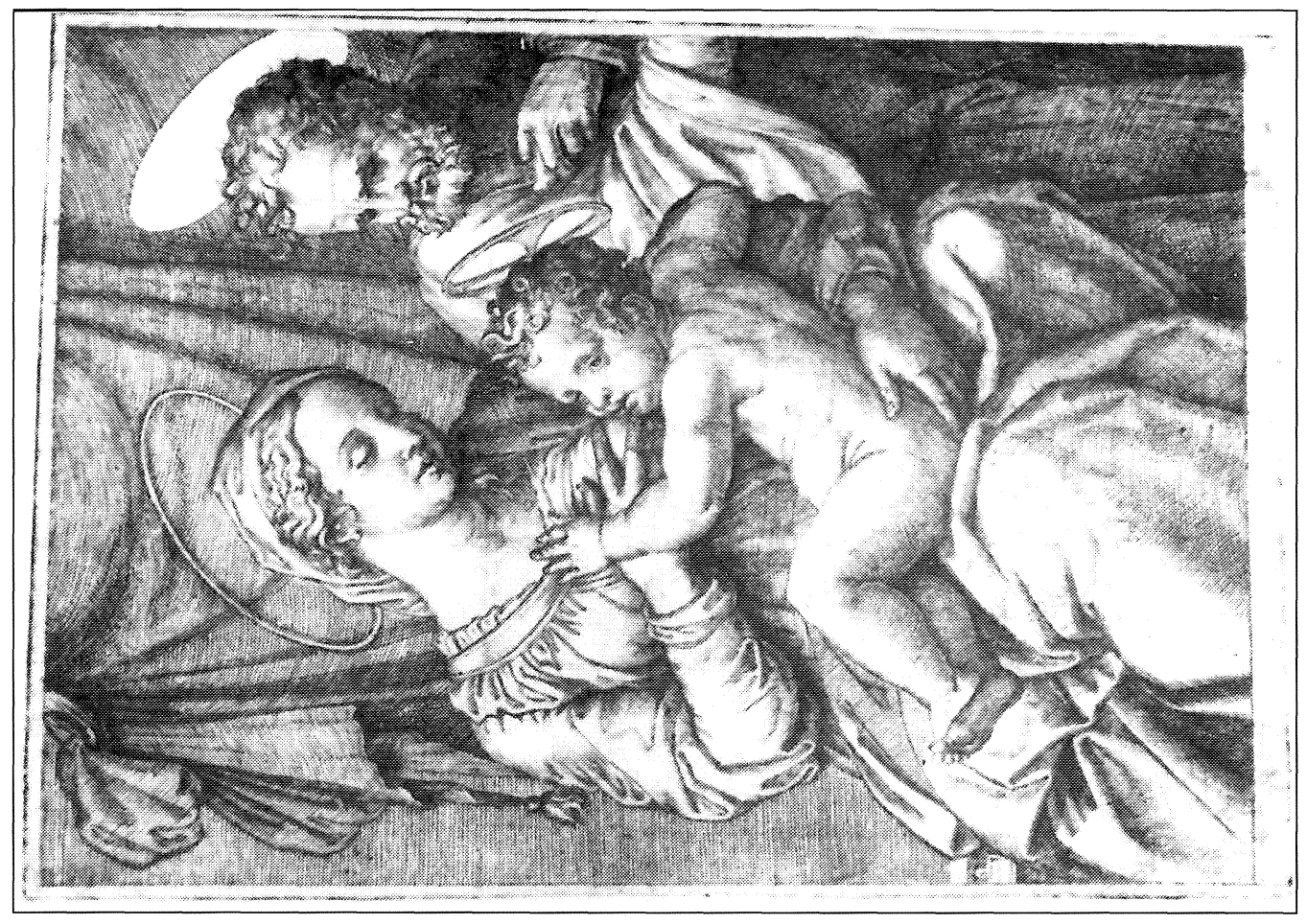

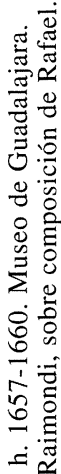

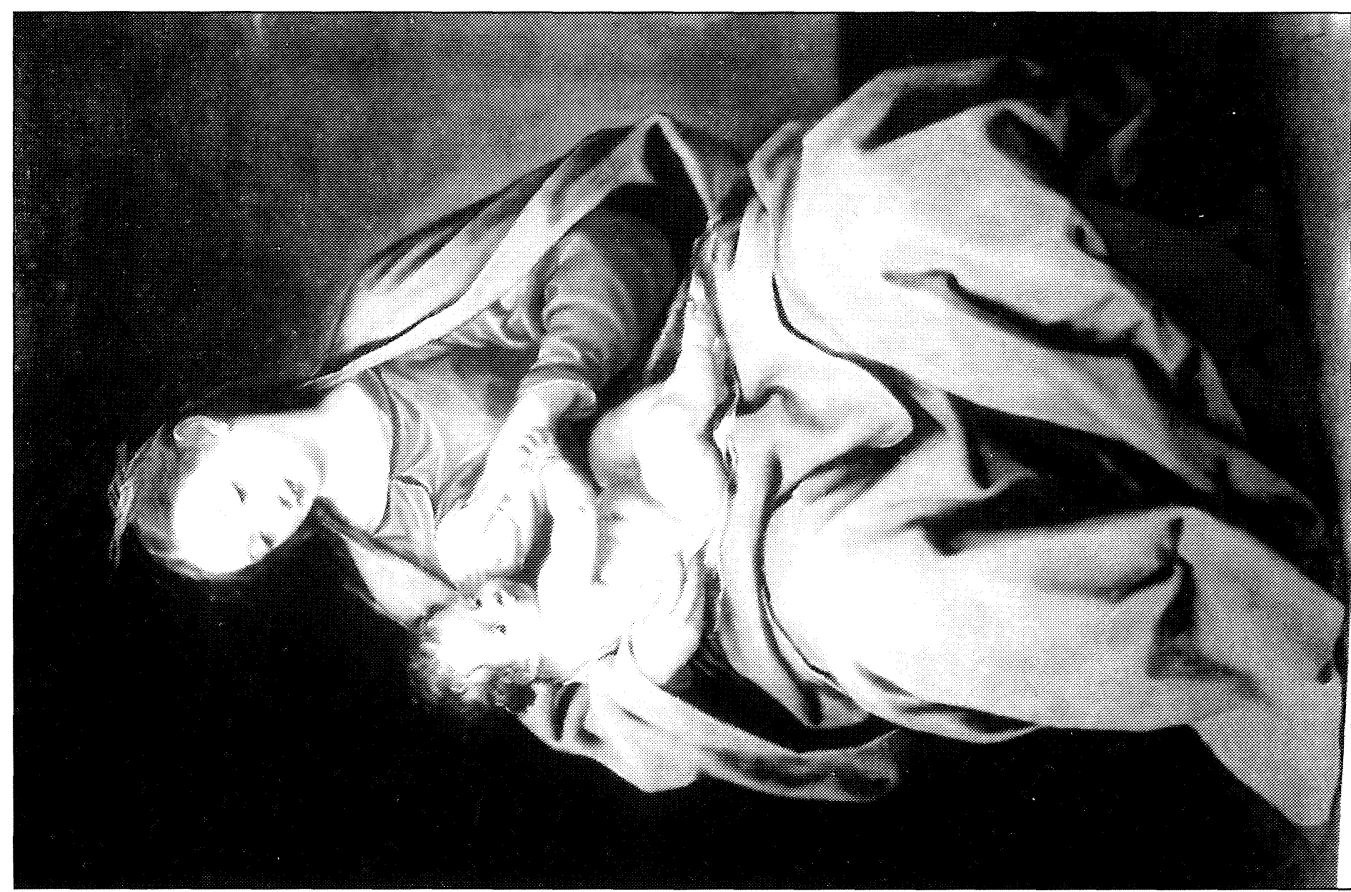

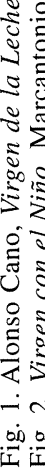


Las medidas encajan bastante bien con las del lienzo de Cano, $164 \times 107 \mathrm{~cm}$. Que esta cita corresponda al lienzo lo apoya el que el otro lienzo con el mismo tema guardado en el $\mathrm{Mu}-$ seo ${ }^{12}$ es de dimensiones más reducidas, $0,67 \times 0,64$, ni tan siquiera una vara. No hay más cuadros con este tema en el museo.

Se da además la paradoja, sea cierta o no, de que se guarda una copia en el Convento de Carmelitas Calzadas de Granada, cenobio de la misma orden que el convento alcarreño, lo que ha presupuesto para algunos especialistas que fue ahí pintada ${ }^{13}$.

Tan sólo en el Monasterio de Santa Ana ${ }^{14}$ de Tendilla hemos constatado la presencia ${ }^{15} \mathrm{de}$ otros lienzos con el tema de la Virgen de la Leche. En este caso se encontraban respectivamente en el Camarín de la Virgen y en el Altar número 3. Aunque el cenobio tuvo importantes bienes, parece más probable que el lienzo de Cano proceda del Convento del Carmen. Muy posiblemente la otra Virgen de la Leche sea alguna de las que se cita en el inventario de desamortización de Tendilla.

Con respecto a las fuentes que inspiraron el cuadro, Wethey ${ }^{16}$ propuso un dibujo del propio Cano guardado en el Museo del Prado, fechado tras las últimas investigaciones ${ }^{17}$ en la década de 1660. Sin embargo es muy probable que el granadino conociese la estampa de la Sagrada Familia (Fig. 2) grabada por Raimondi sobre composición de Rafael. La actitud de la Virgen dando el pecho al niño con suma delicadeza parece inspirarse en el grabado; pero es sobre todo la figura del Niño la que nos ha llevado a este planteamiento. Como puede apreciarse, repite exactamente la posición en el seno de María, así como el gesto de agarrarla mientras gira la cabeza hacia el espectador. El rostro del Niño, con el pelo ligeramente rizado, está también tomado de la estampa.

No parece ser la primera vez que se utilizó esta estampa de Raimondi, y creo interesante apreciar cómo ya Juan de Juanes parece utilizarla en su Virgen de la leche con San Juan Bautista y San Jerónimo (Valencia, parroquia de San Andrés ${ }^{18}$ ). Reducidas las figuras a medio cuerpo, es significativo ver cómo la figura de San José en la estampa ha sido transformada por Juanes en la de San Jerónimo, cambiando algo el gesto y dotándolo de sus correspondientes atributos. Tan sólo parece haber añadido a la composición la figura del Bautista.

Pero mi conjetura va más allá. ¿Hasta qué punto pudo ver Cano esta obra como otra fuente de inspiración para su Virgen de la Leche de Guadalajara? Todos sabemos de la estancia en Valencia del pintor tras el asesinato de su mujer a finales de 1644. El hecho de que ya en la tabla de Juanes el gesto del niño, que deja caer su brazo no en el pecho de la Virgen sino en su mano, se repita exactamente en el lienzo del granadino, puede plantear un hipotético conocimiento de la tabla de Juanes.

No es desde luego una afirmación rotunda, pero creo que es importante advertir el similar parentesco que hay, salvado el estilo y la manera personal de hacer de cada pintor, en ambas composiciones. No parece del todo descabellado que Alonso Cano conociese la tabla

\footnotetext{
12 Varios Autores. Exposición de Pintura de los siglos XVI y XVII, Guadalajara, enero-febrero de 1983 , n. ${ }^{\circ} 6$.

13 Pérez Sánchez, op. cit., p. 69.

${ }^{4}$ El monasterio, fundado a instancias del primer conde de Tendilla, hijo del Marqués de Santillana, sirvió como panteón esta rama de los Mendoza. De él proceden los bellísimos sepulcros de Don Íñigo y su esposa, guardados hoy en la Iglesia de San Ginés de Guadalajara. Mateo Gómez, Isabel. López-Yarto, Amelia. Prados García, José Ma. El arte de la Orden Jerónima. Historia y Mecenazgo, Ediciones Encuentro, Madrid, 1999, pp. 161-162.

15 AHPGU, Sección Desamortización, Caja 76, año 1855, Inventario del monasterio de Santa Ana de Tendilla.

16 Wethey, op.cit., fig. 149.

17 Varios autores, Alonso Cano. Dibujos, Museo del Prado, Madrid, 2001, p. 136, n. ${ }^{\circ}$ de cat. 24.

${ }_{18}$ La obra procede del convento de Franciscanas de Jerusalén de Valencia. Ver: Benito Doménech, Fernando: Joan de Joanes. Una nueva visión del artista y su obra, Cat. Exposición, Museo de Bellas Artes de Valencia, Valencia, 2000, pp. $170-171$, n. $^{\circ}$ de Cat. 68.
} 
en su lugar de origen, el convento de Franciscanas de Jerusalén de Valencia. Lo que desde luego parece unirlas es una fuente común, el grabado de Raimondi sobre composición de Rafael.

Ángel RodRíguez ReBOLLO Licenciado en Historia del Arte. Universidad Complutense de Madrid 